\title{
Anthropogenic and natural contributions to regional trends in aerosol optical depth, 1980-2006
}

\author{
David G. Streets, ${ }^{1}$ Fang Yan, ${ }^{1,2}$ Mian Chin, ${ }^{3}$ Thomas Diehl, ${ }^{3}$ Natalie Mahowald, ${ }^{4}$ \\ Martin Schultz, ${ }^{5}$ Martin Wild, ${ }^{6} \mathrm{Ye} \mathrm{Wu}^{7}$ and Carolyne $\mathrm{Yu}^{1}$ \\ Received 14 December 2008; revised 7 April 2009; accepted 21 May 2009; published 28 July 2009.
}

[1] Understanding the roles of human and natural sources in contributing to aerosol concentrations around the world is an important step toward developing efficient and effective mitigation measures for local and regional air quality degradation and climate change. In this study we test the hypothesis that changes in aerosol optical depth (AOD) over time are caused by the changing patterns of anthropogenic emissions of aerosols and aerosol precursors. We present estimated trends of contributions to AOD for eight world regions from 1980 to 2006, built upon a full run of the Goddard Chemistry Aerosol Radiation and Transport model for the year 2001, extended in time using trends in emissions of man-made and natural sources. Estimated AOD trends agree well $(R>0.5)$ with observed trends in surface solar radiation in Russia, the United States, south Asia, southern Africa, and East Asia (before 1992) but less well for Organization for Economic Co-operative Development (OECD) Europe $(R<0.5)$. The trends do not agree well for southeast Asia and for East Asia (after 1992) where large-scale inter- and intraannual variations in emissions from forest fires, volcanic eruptions, and dust storms confound our approach. Natural contributions to AOD, including forest and grassland fires, show no significant long-term trends $(<1 \% / \mathrm{a})$, except for a small increasing trend in OECD Europe and a small decreasing trend in South America. Trends in man-made contributions to AOD follow the changing patterns of industrial and economic activity. We quantify the average contributions of key source types to regional AOD over the entire time period.

Citation: Streets, D. G., F. Yan, M. Chin, T. Diehl, N. Mahowald, M. Schultz, M. Wild, Y. Wu, and C. Yu (2009), Anthropogenic and natural contributions to regional trends in aerosol optical depth, 1980-2006, J. Geophys. Res., 114, D00D18, doi:10.1029/2008JD011624.

\section{Introduction}

[2] During the late 1980 s and 1990 s there was a growing awareness that solar radiation reaching the Earth's surface was decreasing [Stanhill and Cohen, 2001; Liepert, 2002; Wild et al., 2004]. This so-called solar "dimming" was thought to be unconnected to changes in the Sun's radiation but rather due to changes in the transmittance of the Earth's atmosphere arising from changes in aerosol concentrations or cloud cover. Measurements seemed to show a consistent dimming from the $1960 \mathrm{~s}$, when reliable data sets became available, through to the 1980s. But in the late 1980s the

\footnotetext{
${ }^{1}$ Argonne National Laboratory, Argonne, Illinois, USA.

${ }^{2}$ Department of Civil and Environmental Engineering, University of Illinois at Urbana-Champaign, Urbana, Illinois, USA.

${ }^{3}$ NASA Goddard Space Flight Center, Greenbelt, Maryland, USA.

${ }^{4}$ Department of Earth and Atmospheric Sciences, Cornell University, Ithaca, New York, USA.

${ }^{5}$ Forschungszentrum Juelich, Juelich, Germany.

${ }^{6}$ Institute for Atmospheric and Climate Science, ETH Zurich, Zurich, Switzerland.

${ }^{7}$ Department of Environmental Science and Engineering, Tsinghua University, Beijing, China.
}

Copyright 2009 by the American Geophysical Union. 0148-0227/09/2008JD011624 dimming seemed to level out and in the 1990s to reverse itself and result in "brightening" at widespread locations [Wild et al., 2005, 2007; Pinker et al., 2005]. This so-called "dimming-brightening transition" generated interest in the time development of solar irradiance, in the collection of measurements from ground stations and a new generation of satellites, and in speculation as to the reason for the transition. A review of global dimming-brightening has recently been prepared by Wild [2009].

[3] Dutton et al. [2006] analyzed an observational record of surface solar irradiance at four remote NOAA/GMD sites and an additional site at Boulder, Colorado, covering the period 1977-2004 and found a decreasing tendency in the early part of the record and an increasing tendency at the end. Norris and Wild [2007] analyzed radiation fluxes over Europe from the Global Energy Balance Archive (GEBA) for 1965-2004 in an attempt to separate the influences of cloud cover and aerosols. After removal of the cloud cover effect, they found a trend of declining flux during 19711986 and increasing flux from 1987 to 2002, which they attributed to changes in anthropogenic aerosols. Solar irradiance measurements from Northern Germany and Switzerland also showed a decline in Aerosol Optical Depth (AOD) since the 1980s, including sun photometer and 
precision filter radiometer measurements [Ruckstuhl et al., 2008]. Global and regional observational records have now been updated to 2005 by Wild et al. [2009].

[4] Analysis of radiance measurements from the satellite sensor of the Advanced Very High Resolution Radiometer (AVHRR) appeared to reveal a general downward trend in aerosol optical thickness over the ocean throughout the period 1981-2005 [Mishchenko et al., 2007] but with some interesting regional differences [Mishchenko and Geogdzhayev, 2007]. There was no apparent transition to brightening in the globally averaged AVHRR record up to 2005 reported by Mishchenko et al. [2007], though stratospheric aerosols generated by the volcanic eruptions of El Chichon (1982) and Mount Pinatubo (1991) are strongly present in the data. The authors caution that AVHRR "is not an instrument designed for accurate aerosols retrieval from space" [Mishchenko et al., 2007].

[5] Analysis of AVHRR data for 1981-2001 by Zhao et al. [2008] also found a steady decline in AOD, but with markedly different trends for oceanic regions near the industrialized countries and rapidly developing countries, as well as for regions influenced by Saharan dust or biomass burning smoke. Chylek et al. [2007] further analyzed AVHRR AOD trends (1985-2005) and MISR AOD trends (2000-2006) over the ocean with similar findings, focusing on declining trends near the United States and Europe. Recent MODIS aerosol products over both land and ocean were analyzed by Remer et al. [2008] for 2002-2006 finding the highest AOD values over North Africa, India, East Asia, and southeast Asia, with the lowest values over North America, Europe, Siberia, and Australia. Highly seasonal behavior was observed in biomass burning regions (South America, southern Africa, and Indonesia).

[6] Kvalevåg and Myhre [2007] modeled regional dimming during the industrial age (1750-2000) with a radiative transfer model and concluded that dimming is most pronounced in central Africa, southeast Asia, Europe, and northeast America. Analysis of nine climate models [Romanou et al., 2007] confirmed a general dimming trend during the course of the 20th century but could not support the case for a brightening in the period 1984-2000 because of "significant intrinsic variability." Finally, Alpert et al. [2005] suggested that solar dimming is of a local or regional nature and questioned whether it should be viewed as a global phenomenon. They found a greater rate of decline of solar radiation flux in the GEBA data for 1964-1989 for highly populated areas than for sparsely populated areas. The dimming trend was sharpest for industrial areas of the northern hemisphere. Wild et al. [2008] linked the increasing trend in surface solar radiation over land during the period 1986-2000 with an apparent increase in precipitation over land and intensification of the hydrological cycle.

[7] In previous work [Streets et al., 2006, 2008] we began to test the hypothesis that changes in AOD over time, and particularly the regional transitions from dimming to brightening, are caused by the changing patterns of anthropogenic emissions of aerosols and aerosol precursors. We first developed a global trend in AOD from 1980 to 2000, estimated from the trends in emissions of aerosols and their precursors, and scaled these trends to regional AOD using detailed results from a single-year run of the Goddard Chemistry Aerosol Radiation and Transport (GOCART) model [Streets et al., 2006]. The estimated trend peaked in 1988-1989, supporting the existence of a global dimmingbrightening transition caused by changes in anthropogenic emissions. Recognizing the coarseness of the concept of a global, average AOD and the undoubted high variability of AOD over time and space, we acknowledged that our hypothesis would have a firmer foundation at regional, rather than global, level. Thus, we repeated the analysis for a single region, China, where we felt that the influence of anthropogenic aerosols was likely to be the strongest and therefore the hypothesis more easily tested [Streets et al., 2008]. Again, we found good agreement between the estimated trend of AOD and surface solar radiation observations from a network of 52 weather stations across China. For China, the transition from dimming to brightening seemed to occur about 7 years later than for the global average, in 1995-1996.

[8] In this present paper we extend our previous work by developing a generalized assessment of trends in estimated AOD for eight world regions (United States, Organization for Economic Co-operative Development (OECD) Europe, Russia, South America, southern Africa, south Asia, southeast Asia, and East Asia) for the period 1980-2006. Figure 1 defines the extent of these regions in our study. Our objectives are to (1) confirm or disprove our hypothesis at regional scale; (2) present estimated AOD trends for each region; (3) compare the trends in estimated AOD with trends in observed surface solar radiation; and (4) explain the trends by decomposing them into their anthropogenic and natural components. For this work we incorporate a number of enhancements over our two previous studies: we include time variations in the emissions from natural sources, which were previously assumed to be constant over time; we include all major source types and species contributing to the aerosol mix; and we update the time period of the trends from 2000 to 2006. Forest and grassland fires are included in the natural source category and agricultural burning is included in the anthropogenic source category. We believe that an understanding of the roles of anthropogenic and natural sources in contributing to aerosol concentrations around the world is an important step toward developing efficient and effective mitigation measures for local and regional air quality degradation and climate change.

\section{Methodology}

\subsection{General Methodology Description}

[9] We follow our previous studies [Bond et al., 2004; Streets et al., 2003, 2004, 2006] to develop time-varying, regional emission inventories of black carbon $(\mathrm{BC})$, organic carbon (OC), and sulfur dioxide $\left(\mathrm{SO}_{2}\right)$ from anthropogenic sources, with special attention paid to technology change, which is a controlling factor for fine particle emissions. The detailed 1994 inventory of BC and OC emissions developed by Bond et al. [2004] is extended through time over the period 1980 to 2006 using annual energy statistics. This inventory has also been adapted to calculate $\mathrm{SO}_{2}$ emissions as a precursor of anthropogenic sulfate [Streets et al., 2006]. Further description of the development of the time trends in anthropogenic emissions is provided in section 2.2.

[10] For the purpose of including more realistic variations in natural emissions, we have improved the representation 


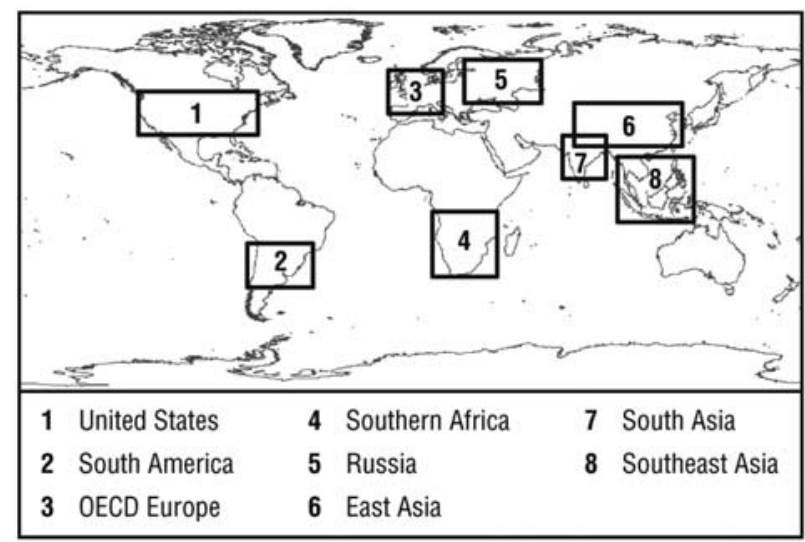

DS100803

Figure 1. Definition of world regions used in this study.

of biomass burning trends by using trends of wildland fire emissions from the RETRO (Reanalysis of the Tropospheric Chemical Composition) project [Schultz et al., 2007, 2008] and the Global Fire Emissions Database (GFED) [van der Werf et al., 2006]. Time trends in a number of other natural emission sources are also introduced (mineral dust, biogenic OC, sea salt, volcanic sulfur, and dimethylsulfide), as described in section 2.3.

[11] Emission strengths and trends are then converted to regional AOD values at $550 \mathrm{~nm}$ using results from the GOCART model [Chin et al., 2002, 2004] for the year 2001 (calculated under all-sky conditions), as in our previous work. Because we use a single-year run of the GOCART model to establish the relationships between source strengths and AOD, we do not capture any year-to-year variability of these relationships that might arise from longterm changes in meteorology, chemistry, and transport; we await full GOCART model runs for each year of the time period against which to compare our results. The GOCART model simulates the major tropospheric aerosol types of sulfate, dust, BC, OC, and sea salt. It uses assimilated meteorological fields from the Goddard Earth Observing System Data Assimilation System (GEOS DAS) [Schubert et al., 1993], which include wind, temperature, pressure, specific and relative humidity, cloud mass flux, cloud fraction, precipitation, boundary layer depth, surface winds, and surface wetness. The spatial resolution of the model is $2^{\circ}$ latitude $\times 2.5^{\circ}$ longitude $\left(\right.$ or $1^{\circ} \times 1.25^{\circ}$ ) with 30 vertical layers. Physical processes in the model include emission, advection, convection, boundary layer mixing, wet deposition (rainout and washout), dry deposition (a function of surface resistance and atmospheric stability), and gravitational settling. Chemical processes include gas and aqueous phase reactions that convert sulfate precursors, such as dimethylsulfide and $\mathrm{SO}_{2}$, to sulfate.

[12] Global emissions of aerosols and their precursors in the GOCART model include anthropogenic emissions of $\mathrm{SO}_{2}, \mathrm{BC}$, and $\mathrm{OC}$ based on recent inventories [Streets et al., 2006; Bond et al., 2004]. Biomass-burning emissions of $\mathrm{SO}_{2}, \mathrm{BC}$, and $\mathrm{OC}$ are estimated from GFED [van der Werf et al., 2006]. Volcanic emissions of $\mathrm{SO}_{2}$ from continuously degassing volcanoes [Andres and Kasgnoc, 1998] are assumed to be constant, and emissions from sporadically erupting volcanoes are constructed from a combination of the Global Volcanism Program database [Siebert and Simkin, 2008 and satellite $\mathrm{SO}_{2}$ data from the Total Ozone Mapping Spectrometer (TOMS) [Carn et al., 2003] and the Ozone Mapping Instrument (OMI) [Krotkov et al., 2006; Carn et al., 2008]. Using a method described by Chin et al. [2000] the injection height, plume thickness, and, if not available from observations, the amount of $\mathrm{SO}_{2}$ emitted are computed on the basis of the magnitude of the volcanic explosivity and the volcanic $\mathrm{SO}_{2}$ index (T. Diehl et al., A global inventory of subaerial volcanic $\mathrm{SO}_{2}$ emissions from 1979 to 2007, manuscript in preparation, 2009).

[13] Other emissions in the model include biogenic emissions of $\mathrm{OC}$ and oceanic emissions of dimethylsulfide and sea salt $(0.1-10 \mathrm{~mm})$, which have been described previously [Chin et al., 2002, 2003]. AOD is determined from the dry mass concentrations and mass extinction efficiencies. The mass extinction efficiencies are calculated from Mie theory on the basis of size distributions, refractive indices, and hygroscopic properties of individual aerosol types. We assume single-mode, lognormal size distributions for sulfate, BC, and $\mathrm{OC}$ aerosols, as well as for each dust and sea salt size bin (details given by Chin et al. [2002]). All aerosol particles are assumed to be externally mixed because of the difficulties in realistically determining the degree of the mixing state.

\subsection{Anthropogenic Emission Trends}

[14] The approach to estimating anthropogenic emissions is based on combining fuel consumption data, the characteristics of combustion technologies, and the application of emission controls, as described by Klimont et al. [2002]. Total emissions for each species and region are given by the equation

$$
\mathrm{Em}_{j, i}=\sum_{l} \sum_{m} \mathrm{FC}_{i, l, m}\left[\sum_{n} \mathrm{EF}_{j, i, l, m, n} X_{i, l, m, n}\right],
$$

where $j, i, l, m$, and $n$ are species, region, sector, fuel type, and technology, respectively; Em is emission; FC is fuel consumption; EF is the net emission factor; and $X$ is the fraction of fuel consumed by a specific technology, where $\sum X=1$ for each fuel and sector. A detailed global inventory of primary $\mathrm{BC}$ and $\mathrm{OC}$ emissions was developed by Bond et al. [2004] on the basis of fuel-use statistics for the year 1996. In previous work [Streets et al., 2004, 2006] we used this inventory to build a regional inventory of $\mathrm{BC}$ and $\mathrm{OC}$ emissions, retaining the detailed accounting of regional variations in technology and other combustion practices. We also include additional technologies (flue gas desulfurization) and new fuel attributes (sulfur contents of all fuels) to enable the model to calculate $\mathrm{SO}_{2}$ emissions using the same energy drivers as for $\mathrm{BC}$ and $\mathrm{OC}$.

[15] We extended the 1996 inventory to all other years in the period 1980-2006 using annual fuel-use trends and economic growth parameters included in the IMAGE model [National Institute for Public Health and the Environment, 2001] developed for the Intergovernmental Panel on Climate Change (IPCC). Fuel use is processed into 112 sector/ fuel/technology combinations [Streets et al., 2004, Table 3]. 
Table 1. Comparison of $\mathrm{SO}_{2}$ Emission Trends for Three World Regions With Other Regional Emission Estimates, 2000-2006 ${ }^{\mathrm{a}}$

\begin{tabular}{|c|c|c|c|c|c|c|}
\hline \multirow[b]{2}{*}{ Year } & \multicolumn{2}{|c|}{ United States } & \multicolumn{2}{|c|}{ OECD Europe } & \multicolumn{2}{|c|}{ East Asia } \\
\hline & This Work & Other $^{\mathrm{b}}$ & This Work & Other $^{\mathrm{c}}$ & This Work & Other $^{\mathrm{d}}$ \\
\hline 2000 & 16.1 & 16.3 & 13.0 & 13.7 & 28.0 & 30.2 \\
\hline 2001 & 15.3 & 15.9 & 13.1 & 13.6 & 28.2 & 31.8 \\
\hline 2002 & 15.0 & 14.8 & 12.9 & 13.2 & 30.4 & 34.3 \\
\hline 2003 & 14.5 & 14.8 & 12.9 & 12.7 & 35.0 & 39.0 \\
\hline 2004 & 14.3 & 14.7 & 12.8 & 11.9 & 39.2 & N/A \\
\hline 2005 & 13.7 & 14.7 & 12.8 & 11.7 & 41.2 & $\mathrm{~N} / \mathrm{A}$ \\
\hline 2006 & 13.1 & 13.5 & 12.8 & 11.5 & 42.3 & N/A \\
\hline
\end{tabular}

${ }^{\mathrm{a}} \mathrm{SO}_{2}$ emission trends given in $\mathrm{Tg} \mathrm{\textrm {SO } _ { 2 }} / \mathrm{a}$.

${ }^{\mathrm{b}}$ From the United States Environmental Protection Agency's National Emission Inventory air pollutant emissions trends data (http://www.epa. gov/ttn/chief/trends/).

${ }^{c}$ From the European Centre on Emissions Inventories and Projections (http://www.ceip.at/emission-data-webdab/). These are expert emissions data from the series "Emissions Used in EMEP Models," in which all European countries are included that are not in other world regions such as Eastern Europe, Russia, and the Middle East.

${ }^{\mathrm{d}}$ From the Japanese Regional Emission Inventory in Asia project (http:// www.jamstec.go.jp/frcgc/research/p3/emission.htm). These data are believed to overestimate $\mathrm{SO}_{2}$ emissions from China. N/A stands for not available.

For three of the regions (United States, OECD Europe, and East Asia), we have compared our $\mathrm{SO}_{2}$ emissions data for the period 2000-2006 with annual statistics of national and regional emissions and other data sources of recent emission trends (Table 1). Considering that different energy driver data and different $\mathrm{SO}_{2}$ control technology data are used for these other studies, the agreement is good. For $\mathrm{SO}_{2}$ emissions in other world regions and for $\mathrm{BC}$ and $\mathrm{OC}$ emissions in all world regions, no such trend data are available to compare against. Trends in regional anthropogenic emissions prior to 2000 in this work are the same as those found by Streets et al. [2006].

\subsection{Natural Emission Trends}

\subsubsection{Mineral Dust Emissions}

[16] Because of the limited observational data sets available to predict mineral aerosol variability, model results are used to develop the decadal trends. Results for interannual variability in mineral aerosols are simulated by the Model of Atmospheric Transport and Chemistry (MATCH) using reanalysis winds for the period 1980-2006 [Luo et al., 2003; Mahowald et al., 2003]. This set of model simulations is driven by the Dust Entrainment and Deposition (DEAD) Model for the source scheme [Zender et al., 2003] and includes wet and dry deposition as described by Luo et al. [2003]. This set of models allows for the interaction between precipitation, soil moisture, and surface winds in generating the mineral aerosols, but not for the effects of changes in vegetation. The model uses the National Center for Environmental Prediction/National Center for Atmospheric Research (NCEP/NCAR) reanalysis data set [Kistler et al., 2001], which represents a combination of model and observations for each 6-h time period, globally for the period 1979-2006. The mineral aerosol source scheme assumes a preferential source area, which is defined as areas with little vegetation situated in regions with topo- graphic lows, where soil particles would collect from runoff [Ginoux et al., 2001]. The simulation has been extensively compared to available observations and has been shown to perform well; it correlates well with climatological dust, daily averaged dust variability, and interannual variability in aerosol concentration and AOD, where such observations are available [e.g., Luo et al., 2003; Mahowald et al., 2003, 2007, 2009; Hand et al., 2004]. There are limited observational data available to evaluate the model's performance on interannual variability. Results are averaged over each study region from Figure 1 and presented as annual time series.

\subsubsection{Biomass Burning Emissions}

[17] To develop estimates of interannual variability in biomass burning over the period of this study we use results from the Reanalysis of the Tropospheric Chemical Composition project, which is designed to analyze long-term changes in the atmospheric budget of trace gases and aerosols from 1960 to 2000 [Schultz et al., 2007, 2008]. RETRO is the first attempt to construct a global emission data set with monthly time resolution over such a long period. The inventory is based on literature reviews, estimates derived from satellite observations, and results from a numerical model with a semiphysical approach to simulating fire occurrence and fire spread. Schultz et al. [2008] introduced a simplified equation for estimating the regional annual carbon releases, $E_{c}$, from fires

$$
E_{c}(i, k)=A(i, k) E_{\text {net }}(i, k),
$$

where $A$ is the burned area in region $i$ and ecosystem class $k$, and $E_{\text {net }}$ is the average amount of carbon emitted per unit area. $E_{\text {net }}$ varies with geographical region and ecosystem type; therefore, the interannual variability is only affected by burned area $A$.

[18] Emissions of 27 trace gas and aerosol compounds in RETRO are derived from constant ecosystem-dependent emission ratios as follows:

$$
E_{i}=E_{c} \frac{E F(i)}{\mathrm{EF}(\mathrm{CO})+\mathrm{EF}\left(\mathrm{CO}_{2}\right)},
$$

where $\mathrm{EF}(\mathrm{CO})$ and $\mathrm{EF}\left(\mathrm{CO}_{2}\right)$ are the emission factors for $\mathrm{CO}$ and $\mathrm{CO}_{2}$, respectively.

[19] Because data in the RETRO project end at 2000, we also investigated use of the Global Fire Emissions Database (GFED) version 2 [van der Werf et al., 2006], which is based on MODIS satellite data and is aimed at quantifying the amount of biomass burned on global scale from 1997 to 2006. For the overlapping period 1997-2000 we found that the geographical distribution and interannual variability in RETRO and GFED agree well [see also Schultz et al., 2008]. We found that the best agreement between RETRO and GFED is for the year 1997; therefore, we constructed a unified set of biomass burning trends that consisted of RETRO data for the period 1980-1996 and GFED data for the period 1997-2006, anchored to the year 1997.

[20] We do not use the outputs from RETRO and GFED directly. Rather we derive the interannual trends of direct carbon emissions for each region and apply them to the open biomass burning values for 1996 from the Speciated Pollutant Emissions Wizard (SPEW) model [Bond et al., 
2004] from which our emissions of $\mathrm{BC}, \mathrm{OC}$, and $\mathrm{SO}_{2}$ are obtained. This ensures consistency between emissions from anthropogenic sources and emissions from biomass burning. From RETRO and GFED, we obtain trends for forest fires (forest fire plus wooded fire) and savanna (grass fire) fires. Thus, open biomass burning of type $n$ (savanna, tropical and extratropical forest) in region $i$ in year $t$ is determined as follows:

$$
\mathrm{FC}_{i, n, t}=\mathrm{FC}_{i, n, 1996, \mathrm{SPEW}} \frac{\mathrm{Em}_{i, n, t}}{\operatorname{Em}_{i, n, 1996}}
$$

where $\mathrm{FC}_{i, n, t}$ is the estimated biomass burning used in this study, $\mathrm{FC}_{i, n, 1996, \mathrm{SPEW}}$ is the biomass burning amount from SPEW, and Em is the emission value from RETRO/GFED. The SPEW model also includes agricultural burning, and for that source category we retain our original trends obtained from IPCC estimates [Nakicenovic et al., 2000; National Institute for Public Health and the Environment, 2001]. For the purpose of categorizing biomass burning as either anthropogenic or natural (section 3.2), we treat agricultural burning as anthropogenic and assume that forest fires and grassland fires are of natural origin. This is an approximation, as we know that many forest and grassland fires can actually be attributed to anthropogenic causes, but the relative proportions of anthropogenic and natural in each region are not known.

\subsubsection{Biogenic Emissions}

[21] Biogenic emission trends are generated by combining emissions from the Model of Emissions of Gases and Aerosol from Nature (MEGAN) [Guenther et al., 2006] over the period 1980-2000 with the representation of the biogenic contribution to organic aerosols in the GOCART model [Chin et al., 2002, 2004] for the year 2001. MEGAN uses near-surface air temperature, solar radiation (including information on cloud cover), folia density or leaf area index, and vegetation type as input parameters. Then it estimates the net terrestrial biosphere emission of isoprene into the atmosphere. The RETRO database [Schultz et al., 2007] contains $\mathrm{CO}$ production from processed regional biogenic emissions from MEGAN from 1960 to 2000, and we used these values to construct our trend. A simple 3-year moving average was applied to extend the trend from 2000 to 2006. The resulting MEGAN-based biogenic emission trend from 1980 to 2006 was applied to the biogenic OC emissions value from GOCART for the year 2001 to develop the 1980-2006 OC trend from biogenic sources, as follows:

$$
\mathrm{Em}_{\text {bio-OC, }, i t}=\mathrm{Em}_{\mathrm{bio}-\mathrm{OC}, i, 2001, \mathrm{GOCART}} \frac{\mathrm{Em}_{\mathrm{CO}, i, t, \mathrm{MEGAN}}}{\operatorname{Em}_{\mathrm{CO}, i, 2001, \mathrm{MEGAN}}},
$$

where $\mathrm{Em}_{\mathrm{bio}-\mathrm{OC}, i, t}$ is the estimated biogenic OC emission in region $i$ in year $t$ in our model; Em bio-OC,i,2001,GOCART is the biogenic OC emission in region $i$ from the GOCART model for the year 2001; $\mathrm{Em}_{\mathrm{CO}, i, t, \mathrm{MEGAN}}$ is the biogenic emission trend in region $i$ in year $t$ (normalized to 2001) from MEGAN.

\subsubsection{Sea Salt Emissions}

[22] Our trends in sea salt emissions are obtained directly from GOCART model simulations for each year of the study period, thereby taking into account real interannual meteorological variability. Sea salt emissions are computed in the GOCART model as a function of the $10-\mathrm{m}$ wind speed and the particle radius, using the approximations of Gong [2003] and Monahan et al. [1986]. This method uses four size bins with dry radii of $0.1-0.5,0.5-1.5,1.5-5.0$, and $5.0-10.0 \mu \mathrm{m}$. For each size bin, the model computes a particle flux $F$ [particles $\mathrm{m}^{-2} \mathrm{~s}^{-1}$ ] by integrating the following formula over the size range of the specific bin

$$
\frac{d F}{d r}=1.373 u_{10}^{3.2} r^{-3}\left(1+0.057 r^{1.05}\right) 10^{1.19 \exp \left(-B^{2}\right)},
$$

where $B=(0.380-\log r) / 0.650, u_{10}$ is the $10-\mathrm{m}$ wind speed $\left(\mathrm{m} \mathrm{s}^{-1}\right)$ and $r$ is the particle radius $[\mu \mathrm{m}]$.

[23] Sea salt aerosols are highly hygroscopic and display strong growth with increasing ambient relative humidity. The above equation holds for particle fluxes at a relative humidity of $80 \%$, i.e., the particle radius has to be provided for this relative humidity value. On the basis of the empirical relationship of Gerber [1985] between dry size and wet size, we use the approximation $r_{\text {wet }}=2 \times r_{\text {dry. }}$. The particle flux is then transformed into a mass flux of dry particles, since GOCART delivers a mass mixing ratio for the dry size only. The 10-m wind speeds are taken from the Goddard Earth Observing System Data Assimilation System version 4 (GEOS-4 DAS). Sea salt emissions are then extracted from the model for each of the regional domains. 2.3.5. Volcanic $\mathrm{SO}_{2}$ Emissions

[24] Trends in volcanic $\mathrm{SO}_{2}$ emissions are derived for both quasi-continuously erupting volcanoes and sporadically erupting volcanoes to generate an emission inventory covering the period 1980 to 2006 (Diehl et al., manuscript in preparation, 2009). For continuous emissions, we use the $\mathrm{SO}_{2}$ emission rates provided by Andres and Kasgnoc [1998] for 47 volcanoes that erupted quasi-continuously during the time frame 1973-1997, with average total emissions of 9.6 $\mathrm{Tg} \mathrm{SO}_{2}$ per year. We assume that their state of activity has not significantly changed in recent years compared to the 25-year period.

[25] Emission amounts from sporadically erupting volcanoes are estimated from data provided by the Global Volcanism Program (GVP) of the Smithsonian Institution [Siebert and Simkin, 2008]. This database includes, among other entries, the eruption start date and end date, longitude, latitude, elevation, and the Volcanic Explosivity Index (VEI) [Newhall and Self, 1982] of volcanic eruptions up to 2007. When available, the VEI is used to estimate the amount of $\mathrm{SO}_{2}$ emitted by the given eruption on the basis of a relationship found by Schnetzler et al. [1997]. These VEI calculations form a general default data source that is used when there are no reported data for specific volcanoes or events. However, there are often better sources for individual volcanic sources that can be retrieved from the literature to replace or amend the VEI-derived values. Examples of such data sources are observations from the TOMS or OMI instrument [Carn et al., 2003, 2008] and an updated version of this data set (S. A. Carn, personal communication, 2006). We also use some $\mathrm{SO}_{2}$ results from Correlation Spectrometer (COSPEC) measurements, specifically for the unusually large degassing of the Miyakejima volcano in Japan, starting in August 2000 [Kazahaya et al., 2004]. The range of global $\mathrm{SO}_{2}$ from sporadically emitting volcanoes in our inventory 
Table 2. Emissions, Total Mass Burden, and AOD by Region for $2001^{\mathrm{a}}$

\begin{tabular}{lcccccc}
\hline Region & Parameter $^{\mathrm{b}}$ & Sulfur & BC & OC & Sea Salt & Dust \\
\hline United States & Emissions & 8.05 & 0.36 & 1.62 & 11.67 & 8.24 \\
& Total mass burden & 0.03 & 0.00 & 0.02 & 0.07 & 0.61 \\
South America & AOD & 0.07 & 0.00 & 0.01 & 0.00 & 0.03 \\
& Emissions & 2.25 & 0.27 & 2.00 & 43.46 & 20.43 \\
& Total mass burden & 0.01 & 0.00 & 0.03 & 0.10 & 0.13 \\
OECD Europe & AOD & 0.04 & 0.00 & 0.02 & 0.01 & 0.01 \\
& Emissions & 6.02 & 0.30 & 0.50 & 27.03 & 0.00 \\
& Total mass burden & 0.02 & 0.00 & 0.01 & 0.10 & 0.41 \\
Russia & AOD & 0.10 & 0.01 & 0.01 & 0.02 & 0.05 \\
& Emissions & 3.99 & 0.19 & 0.97 & 0.20 & 0.00 \\
Southern Africa & Total mass burden & 0.02 & 0.00 & 0.01 & 0.05 & 0.63 \\
& AOD & 0.14 & 0.01 & 0.02 & 0.01 & 0.06 \\
South Asia & Emissions & 2.55 & 1.40 & 1.14 & 28.71 & 17.73 \\
& Total mass burden & 0.02 & 0.02 & 0.13 & 0.09 & 0.12 \\
& AOD & 0.04 & 0.02 & 0.07 & 0.01 & 0.01 \\
East Asia & Emissions & 3.33 & 0.55 & 1.93 & 14.21 & 16.36 \\
& Total mass burden & 0.01 & 0.01 & 0.02 & 0.05 & 0.59 \\
& AOD & 0.08 & 0.01 & 0.03 & 0.01 & 0.06 \\
Southeast Asia & Emissions & 16.16 & 1.72 & 4.43 & 18.29 & 281.2 \\
& Total mass burden & 0.08 & 0.02 & 0.06 & 0.31 & 3.84 \\
& AOD & 0.11 & 0.01 & 0.02 & 0.01 & 0.08 \\
& Emissions & 2.48 & 0.59 & 3.46 & 56.00 & 0.00 \\
& Total mass burden & 0.02 & 0.01 & 0.04 & 0.13 & 0.12 \\
& AOD & 0.05 & 0.01 & 0.02 & 0.01 & 0.01 \\
\hline
\end{tabular}

${ }^{\mathrm{a}}$ Results for Sulfur, BC, OC, and sea salt are from the GOCART model. Results for dust are from the MATCH model, as described in the text.

${ }^{\mathrm{b}}$ Emissions are given in $\mathrm{Tg} \mathrm{M} / \mathrm{a}$, and total mass burden is given in $\mathrm{Tg} \mathrm{M}$.

is from $4.1 \mathrm{Tg}$ per year in 1983 to $30.5 \mathrm{Tg}$ per year in 1991, with a median value of $7 \mathrm{Tg}$ per year.

\subsubsection{Dimethylsulfide Emissions}

[26] Trends in dimethylsulfide (DMS) emissions are also taken from GOCART model simulations for each year [Chin et al., 2000]. The mass flux of DMS is derived from the surface water concentration of DMS and the sea-to-air transfer velocity of DMS. The surface water concentration is taken from a database compiled by Kettle et al. [1999], who used over 15,000 point measurements to generate a climatology of monthly $1^{\circ} \times 1^{\circ}$ global maps of the DMS concentration $\left(\mathrm{nmol} \mathrm{dm}{ }^{-3}\right)$ at the seawater surface. The transfer velocity $k_{w}\left(\mathrm{~cm} \mathrm{~h}^{-1}\right)$ is computed with an empirical relationship found by Liss and Merlivat [1986] for three velocity regimes: $k_{w}=0.17 \mathrm{u}_{10}$ for $u_{10} \leq 3.6 ; k_{w}=2.85 u_{10}$ 9.65 for $3.6<u_{10} \leq 13$; and $k_{w}=5.9 u_{10}-49.3$ for $u_{10}>$ 13 , where $u_{10}$ is again the $10-\mathrm{m}$ wind speed in $\mathrm{m} \mathrm{s}^{-1}$, taken from the GEOS-4 DAS. This relationship holds for gases with a Schmidt number $S c$ of about $600\left(S c=v D^{-1}\right.$, where $v$ is the kinematic viscosity and $D$ is the molecular diffusivity). In order to extend this relationship to other Schmidt numbers, we assume that $k_{w}$ is proportional to $S c^{-2 / 3}$ for $u_{10} \leq 3.6 \mathrm{~m} \mathrm{~s}^{-1}$ and to $S c^{-1 / 2}$ for $u_{10}>3.6 \mathrm{~m} \mathrm{~s}^{-1}$ [Liss and Merlivat, 1986]. The diffusion of DMS within the surface water is from Saltzman et al. [1993]

$$
S c=2674.0-147.12 t+3.726 t^{2}-0.038 t^{3},
$$

where $t$ is the sea surface temperature $\left[{ }^{\circ} \mathrm{C}\right]$, taken from GEOS-4 DAS.

\subsection{Estimated AOD Trends}

[27] To construct annual trends in AOD from 1980 to 2006, we first establish a relationship between AOD and the emission strengths of the various aerosol precursors in each region from a single-year, full model run of the GOCART model, as described in previous work [Streets et al., 2006, 2008]. In this study we use annual AOD and aerosol emissions for the year 2001 from a GOCART (version c3.1) model run. We use GOCART results for sulfate, BC, $\mathrm{OC}$, and sea salt; for mineral dust we use the MATCH model calculations described in section 2.3.1. The resulting relationships among emissions, total mass burden, and AOD are summarized in Table 2 for each world region. A convenient way to represent the relationship between $\mathrm{AOD}$ and emissions is

$$
\tau_{j, i, t}=f_{j, i} \mathrm{Em}_{j, i, t},
$$

where $j, i$, and $t$ are species, region, and year, respectively; $\tau$ is the estimated AOD; $f(\mathrm{a} / \mathrm{Tg})$ is the modeled relationship between AOD and emission mass for the year 2001 from GOCART; and Em is the annual emission rate (Tg/a).

[28] The effect of aerosols in the atmosphere is to induce a measurable reduction in surface solar radiation. Sheridan and Ogren [1999] observed that aerosol direct radiative effects at the surface are linearly proportional to the aerosol optical depth (i.e., the higher the AOD, the less solar radiation reaches the surface). On the basis of measurements and model simulations in China, Xia et al. [2007] found that surface irradiance varies linearly with AOD when AOD is less than about 0.5 , but that an exponential function is more suitable for the overall relationship. The annual AOD in our model is less than 0.5 except for Russia (actually the Soviet Union) before about 1990. Our comparison is based on the classical equation

$$
I / I_{0}=\exp [-\tau]
$$

where $I$ is the intensity of radiation at the surface, $I_{0}$ is the intensity of radiation at the source (assumed to be constant), and $\tau$ is the AOD.

[29] Therefore, the trends of estimated $\exp [-\mathrm{AOD}]$ should be comparable with the trends of observed surface solar radiation. Because the AOD is estimated for a single wavelength $(550 \mathrm{~nm})$, the attenuation of solar radiation obtained from this equation may not be representative for other wavelengths or for the solar spectrum as a whole; also this relationship is for direct, not diffuse radiation. In addition, this relationship can only be expected to be uniform over time if the aerosol composition does not change significantly, as discussed further in section 2.5. For ease of comparison of estimated $\exp [-\mathrm{AOD}]$ and surface solar radiation observations, both data sets are normalized as follows:

$$
x_{i}^{\prime}=\frac{x_{i}-\bar{x}}{\sigma},
$$

where $x^{\prime}$ is the normalized variable, $\bar{x}$ is the average of $x$, and $\sigma$ is the standard deviation. 


\subsection{Surface Solar Radiation Observations}

[30] Solar radiation reaching the surface is significant to research of climate change and global warming because it can indicate anthropogenic disturbances [Ramanathan et al., 2001; Liepert, 2002]. Widespread direct measurements of surface solar radiation started after the International Geophysical Year in 1957-1958, which makes long-term study feasible even though the reliability of early measurements has been questioned [World Climate Research Programme, 1991].

[31] The observational data used in this study are a subset of the data reported by Wild et al. [2009]. We compiled observational data representative of each of our world regions from the best and most reliable sites that had a stable period of operation between 1980 and 2005 (no 2006 data were available). Measurements are all-sky, consistent with the estimated AOD. The major networks used are as follows: (1) the Global Energy Balance Archive (GEBA), which was established at the Swiss Federal Institute of Technology and is maintained by the World Radiation Data Center (WRDC) [Gilgen et al., 1998]; (2) the Baseline Surface Radiation Network (BSRN) initiated by the World Climate Research Programme (WCRP) [Ohmura et al., 1998]; (3) the Surface Radiation Budget Network (SURFRAD) in the United States, which commenced operation in 1993 through the support of the National Oceanic and Atmospheric Administration [Augustine et al., 2000]; (4) the Earth System Research Laboratory (GMD, formerly known as the Climate Monitoring and Diagnostics Laboratory, CMDL) [Schnell, 2004; Dutton et al., 2006]; (5) the U.S. Department of Energy ARM (Atmospheric Radiation Measurement) Program [Ackerman and Stokes, 2003]; and (6) the radiation database of the Swiss Meteorological Institute. We develop and use annual average radiation data from each chosen site to investigate potential climatologically significant variations, because shorter averaging intervals are strongly influenced by interannual variations that complicate the long-term statistical analysis. Site data are grouped and combined for each of our world regions.

[32] For the United States, continuous solar radiation records for multiple sites are not available until the mid1990s. Although accurate measurements started in the 1970s in the United States, there were only two observational sites (Boulder and Barrow) at that time. All-sky insolation data from seven sites over the period 19952005 are used for the United States in this study; this limits the time period available for analysis and interpretation. Long et al. [2009] have recently summarized observations in the United States. For southern Africa, data from seven sites in Mozambique, Harare, and South Africa are used. For Russia (including the Soviet Union in early periods), we bring together updated information from 30 sites extending to 2005 . However, during the period 1995-2002, only one site in Odessa provides reliable solar radiation data. For OECD Europe most data for the period 1980-2005 are available from GEBA and the Swiss Meteorological Institute. They are grouped into eight regions (Austria and Switzerland, Scandinavia, France, Germany, U.K. and Ireland, Belgium and Netherlands, Italy, Spain and Portugal) with 110 sites in all [Wild et al., 2009]. For south Asia, we include four sites in India [Wild et al., 2005; Ramanathan et $a l ., 2005]$. For East Asia, data from four countries are used:
Japan (14 sites), China (7 sites), Mongolia (3 sites) and Korea (4 sites). For southeast Asia, we apply information from nine sites in Thailand, Singapore, Malaysia, Indonesia, and the Philippines.

[33] Figure 2 presents the annual mean surface solar radiation observations that we used in our analysis for each world region (except South America, for which there are insufficient data available at present). The annual time series for each region is determined by averaging the annual means of observations at individual sites. The vertical bars represent \pm 1 standard deviation in each region in each year, illustrating the variability of measurements across different sites within a region. The variability within a region for a given year is larger than the interannual variability of the averages for all regions except southern Africa. In this work we are more concerned with the trends and the variability of AOD and surface solar radiation over a long time period than with the absolute values. Therefore, the annual average estimates of surface solar radiation are subsequently normalized, as shown in equation (10).

[34] In section 3.3 the estimated trends in $\exp [-\mathrm{AOD}]$ obtained using the method described in section 2.4 are compared with the trends in surface solar radiation from site measurements in each region. The results are analyzed to identify trends in both anthropogenic and natural sources over the time period, as well as the extent of agreement between estimates and observations. We should caveat our comparison of AOD with the attenuation of solar radiation. This method does not take into account the differences in "forcing efficiency," the attenuation of solar radiation per unit AOD, among different aerosol components. For example, the forcing efficiency of $\mathrm{BC}$ can be an order of magnitude higher than sulfate or OC aerosol, even though its AOD may be rather small, as shown by Schulz et al. [2006]. Therefore, the surface solar radiation trends may not follow the AOD trends over a particular region if the aerosol composition changes significantly over time in that region. However, because the aerosol composition remains relatively stable in each region on an annual basis (i.e., BC, OC, and sulfate tend to move together in a given region under the various driving forces, so that their relative contributions tend to stay the same) and because only normalized trends are analyzed, our comparison is expected to be valid.

\section{Results and Discussion}

\subsection{Estimated AOD Trends}

[35] Estimated regional AOD trends are presented for each region in Table 3 and Figure 3. We present Table 3 and Figure 3 to give an idea of the absolute magnitudes of AOD estimated in this work. Our estimated AOD values range from a low of 0.08 (in the United States in 2006 and southeast Asia in 1980) to a high of 0.62 (Russia in 1980) in our model. Because they are driven by GOCART values for 2001, the absolute values of estimated AOD are similar to those generated by the full GOCART model and previously compared with observations. Our estimated trends show significant rates of AOD decline during the period 19802006 in Russia (annual average decline of 4.1\%), the United States $(2.9 \%)$, OECD Europe (1.1\%), and South America $(0.7 \%)$. Increases are evident in southeast Asia (5.6\%), East Asia (2.8\%), south Asia (2.0\%), and southern Africa 

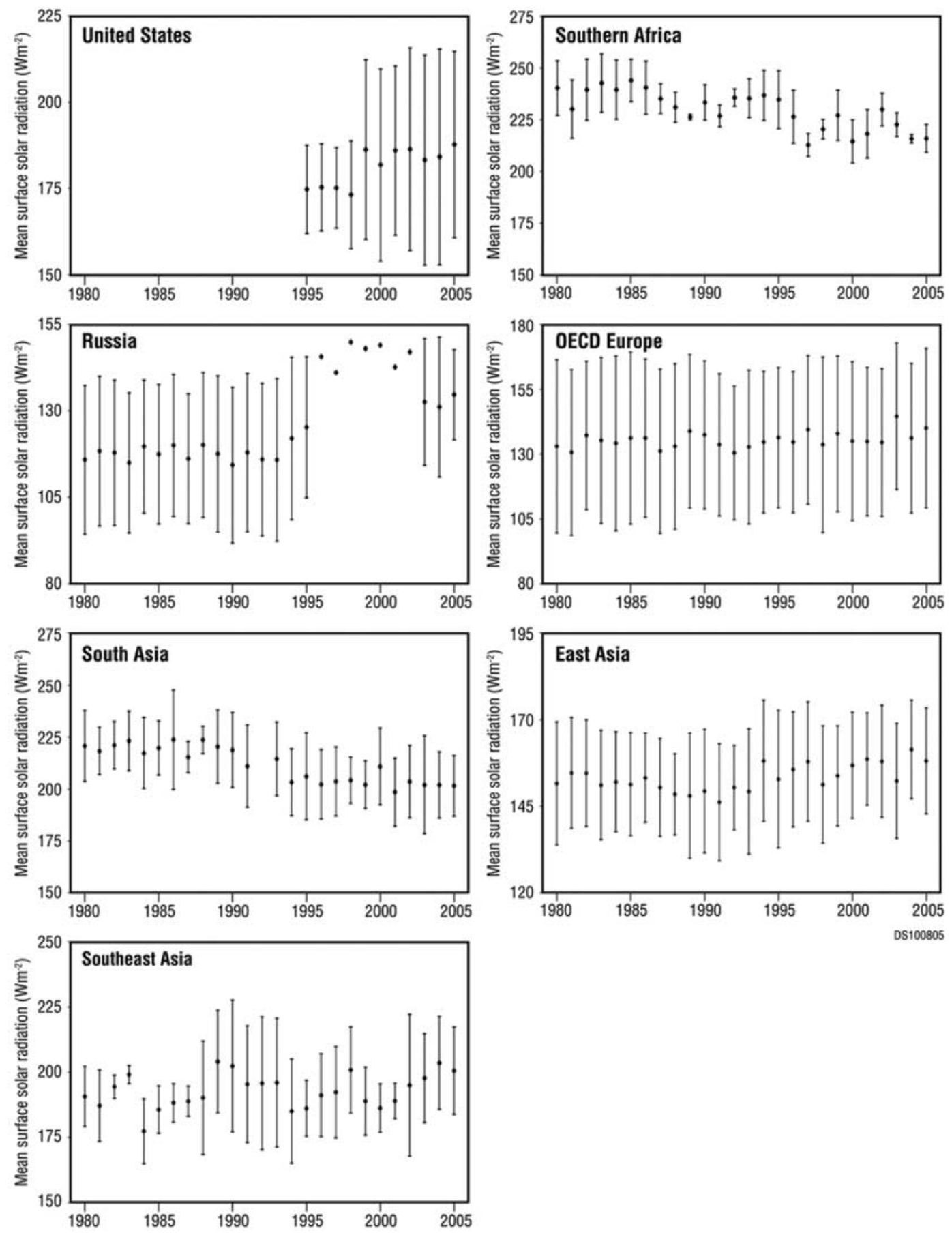

Figure 2. Annual means of observed surface solar radiation for each region, 1980-2005 (vertical bars represent \pm 1 standard deviation). 
Table 3. Regional Estimated AOD Changes From 1980 to 2006

\begin{tabular}{|c|c|c|c|c|}
\hline \multirow[b]{2}{*}{ Region } & \multicolumn{2}{|c|}{ AOD } & \multirow{2}{*}{$\begin{array}{c}\text { Change } \\
1980-2006 \\
(\%)\end{array}$} & \multirow{2}{*}{$\begin{array}{c}\text { Annual Rate } \\
1980-2006 \\
(\%)\end{array}$} \\
\hline & 1980 & 2006 & & \\
\hline United States & 0.13 & 0.08 & -38.0 & -2.94 \\
\hline South America & 0.19 & 0.17 & -10.1 & -0.66 \\
\hline Southern Africa & 0.10 & 0.10 & 5.6 & 0.34 \\
\hline OECD Europe & 0.31 & 0.26 & -16.0 & -1.08 \\
\hline Russia & 0.62 & 0.32 & -48.9 & -4.11 \\
\hline South Asia & 0.21 & 0.29 & 37.7 & 2.02 \\
\hline East Asia & 0.17 & 0.26 & 54.3 & 2.75 \\
\hline Southeast Asia & 0.08 & 0.20 & 137.4 & 5.55 \\
\hline
\end{tabular}

$(0.3 \%)$. Southeast Asia shows two large peaks reaching to AOD values of about 0.35 , corresponding to the Mt. Pinatubo volcanic eruption in 1991 [Abakumova et al., 1996; McCormick et al., 1995; Schwartz, 2005] and the huge forest fires in Indonesia in 1997. These kinds of aperiodic increases in emissions are discussed more fully in section 3.3.

\subsection{Estimated AOD Contributions From Natural and Anthropogenic Aerosols}

[36] In Figure 4 we present the estimated regional AOD trends for natural sources (forest and grassland fires, sea salt, dust, biogenic OC, volcanic sulfur, and dimethylsulfide); and in Figure 5 we present the estimated regional AOD trends for man-made sources (sulfate, BC, and OC from anthropogenic activities, including fossil fuel combustion, biofuel combustion, industrial process sources, and agricultural burning). For the natural source trends, significant interannual variability can be seen, usually associated with elevated $\mathrm{OC}$ from biomass burning events or sulfate from volcanic eruptions, most notably in the southeast Asia record. However, the long-term changes in natural emissions are small. Over most regions, the least squares slopes of the AOD trends are less than 0.001, meaning that the annual changes are less than $1 \%$. The two exceptions are South America (-0.0013) and OECD Europe $(+0.0019)$. Both of these trends are associated primarily with slow changes in the amounts of $\mathrm{OC}$ released from biomass burning, in South America a decrease and in OECD Europe an increase.

[37] Figure 5 shows that trends in estimated AOD for anthropogenic sources are much smoother than for natural sources with no abrupt year-to-year variations. Changes above and beyond monotonic increases or decreases usually take place over periods of 5 years or so, corresponding to the inertia of human institutions and technological change. Sulfate mainly controls the AOD trends from anthropogenic aerosols; $\mathrm{BC}$ and $\mathrm{OC}$ generally exhibit little variation and have relatively small contributions to total anthropogenic AOD. To a large extent, the changes in $\mathrm{BC}$ and $\mathrm{OC}$ mirror the changes in sulfate. Therefore, we concern ourselves with the changes in AOD from sulfate in this section. For the United States, OECD Europe, and Russia, estimated AOD from anthropogenic sulfate has decreased by $43 \%, 45 \%$, and $55 \%$, respectively, over the 26 -year period, corresponding to annual average rates of decline of $2.1 \%, 2.3 \%$, and $3.0 \%$, respectively. For South America, southern Africa, south Asia, East Asia, and southeast Asia, the AOD contribution from anthropogenic sulfate has increased by annual average rates of $0.9 \%, 1.3 \%, 5.4 \%, 3.1 \%$, and $3.6 \%$, respectively, which are consistent with the anthropogenic $\mathrm{SO}_{2}$ emission inventory of Smith et al. [2001]. Because AOD is proportional to emission mass over the range of AOD values seen in this study, we can consider the changes of AOD from anthropogenic sulfate to be closely tied to changes in $\mathrm{SO}_{2}$ emissions. If oxidants changed significantly during the study period, then the relationship between $\mathrm{SO}_{2}$ and sulfate may have been disturbed; for most regions, this is unlikely to be the case, but we wonder if this might partly explain the deviation of estimated AOD from observations in East Asia after 2000. In this region, for example, ozone concentrations increased markedly after 2000. From the modeling study of Manktelow et al. [2007] for the United States, Western Europe, and East Asia, the mean rate of change in anthropogenic $\mathrm{SO}_{2}$ emissions between 1985 and 2000 was $-1.9 \%,-3.4 \%$ and $+2.5 \%$. In the earlier work of Streets et al. [2000], the annual average growth rates of $\mathrm{SO}_{2}$ emissions for south Asia, East Asia, and southeast Asia during $1985-1997$ were $5.3 \%, 2.4 \%$, and $7.2 \%$, respectively, which can be expected to have decreased somewhat since 1997 because of sulfur-in-fuel limits that took effect in China, South Korea, Taiwan, and Thailand [Streets et al., 2000, Table 2].

[38] Table 4 shows the contributions of each of the major aerosol source types to estimated AOD in each region averaged over the entire period 1980-2006. The dominant role of anthropogenic sulfate is apparent in the industrialized regions of Russia (74\%), the United States $(67 \%)$, OECD Europe (51\%), and East Asia (46\%). Anthropogenic OC is prominent in south Asia (13\%), as a result of

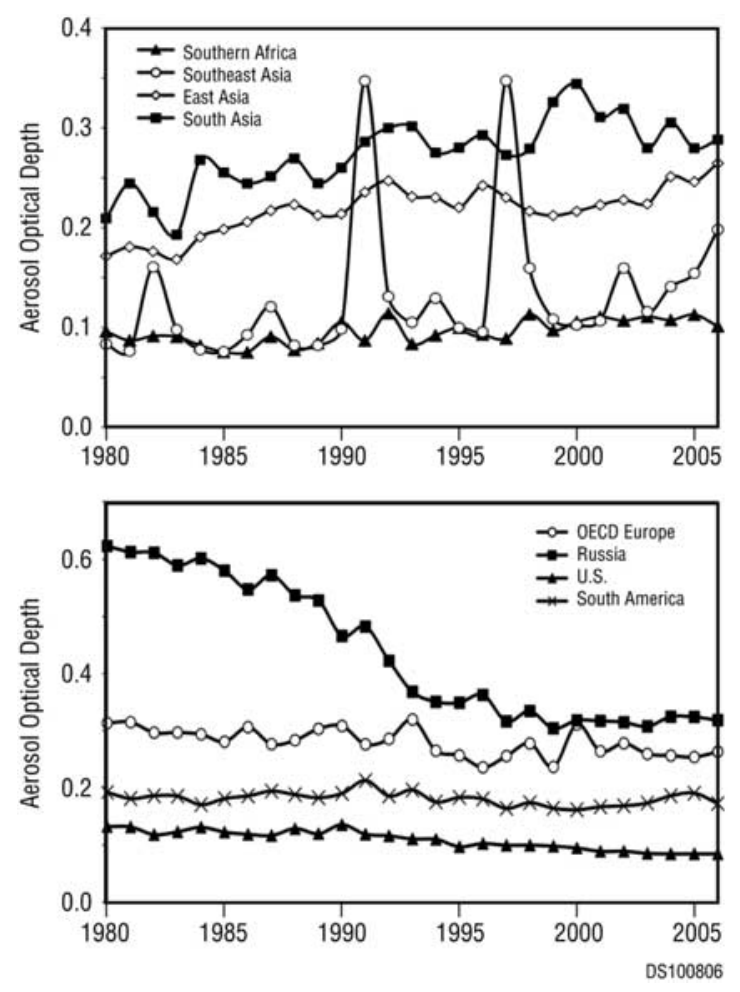

Figure 3. Estimated AOD trends for each world region from 1980 to 2006 . 

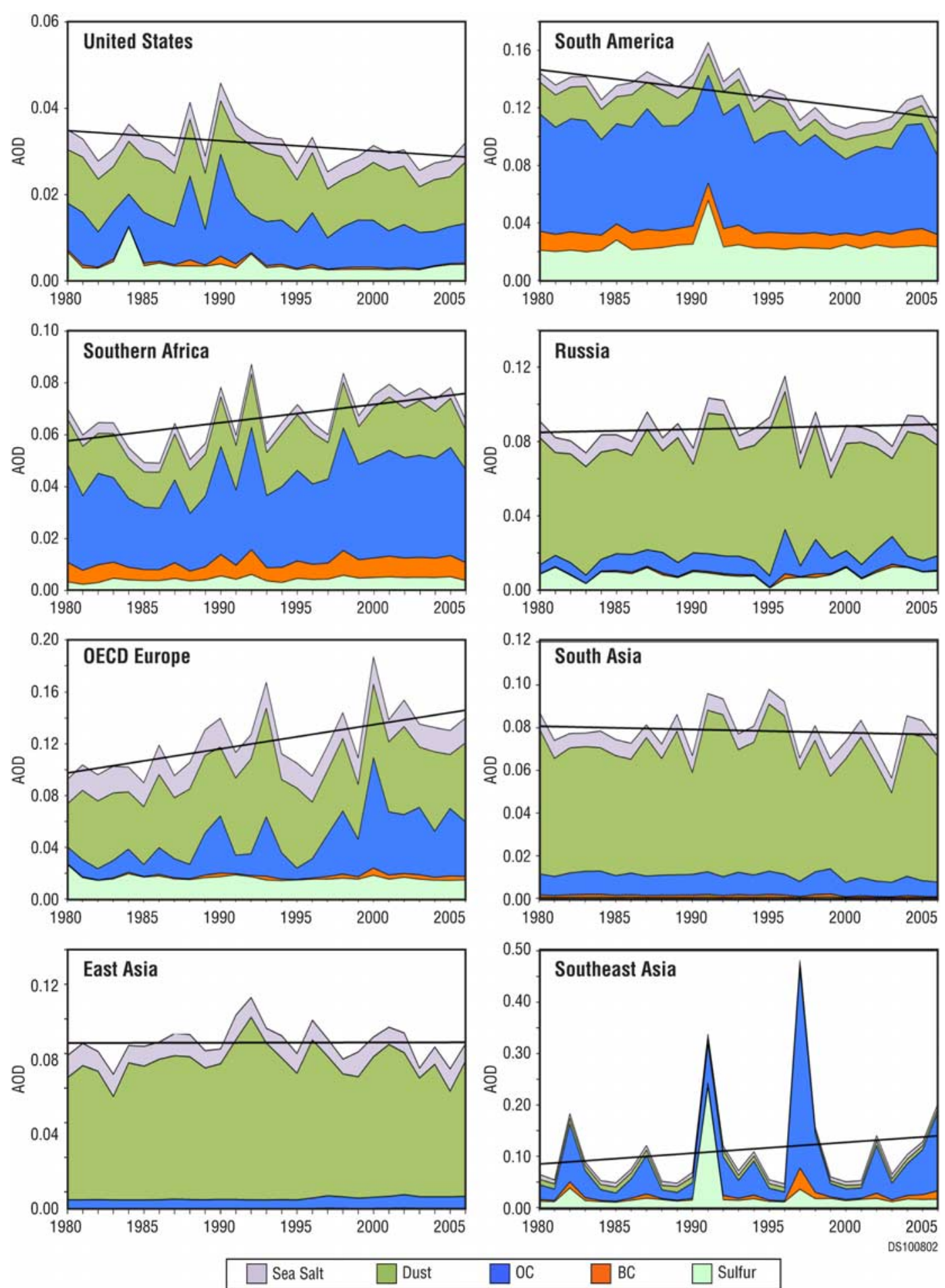

Figure 4. Estimated AOD trends for natural aerosols in each region, 1980-2006.

extensive biomass and biofuel burning. Natural OC aerosol shows major contributions in the forested regions of South America (39\%), southern Africa (36\%), and southeast Asia (34\%). Mineral dust is an important contributor in the dry or desertified regions of East Asia (37\%) and south Asia (35\%). Volcanic sulfur is evident in South America (13\%) and southeast Asia (14\%).

[39] Table 4 also summarizes the relative contributions of anthropogenic and natural sources to total AOD in each region. Anthropogenic aerosols dominate in Russia (79\%), the United States (74\%), OECD Europe (56\%), south Asia (55\%), and East Asia (55\%); whereas natural aerosols dominate in South America (71\%), southern Africa (70\%), and southeast Asia (66\%). These findings are consistent with analysis of GOCART model results [Chin et al., 2004], the analysis of MODIS satellite observations [Remer et al., 2008], and the modeling study of Kvalevaig and Myhre [2007]. 

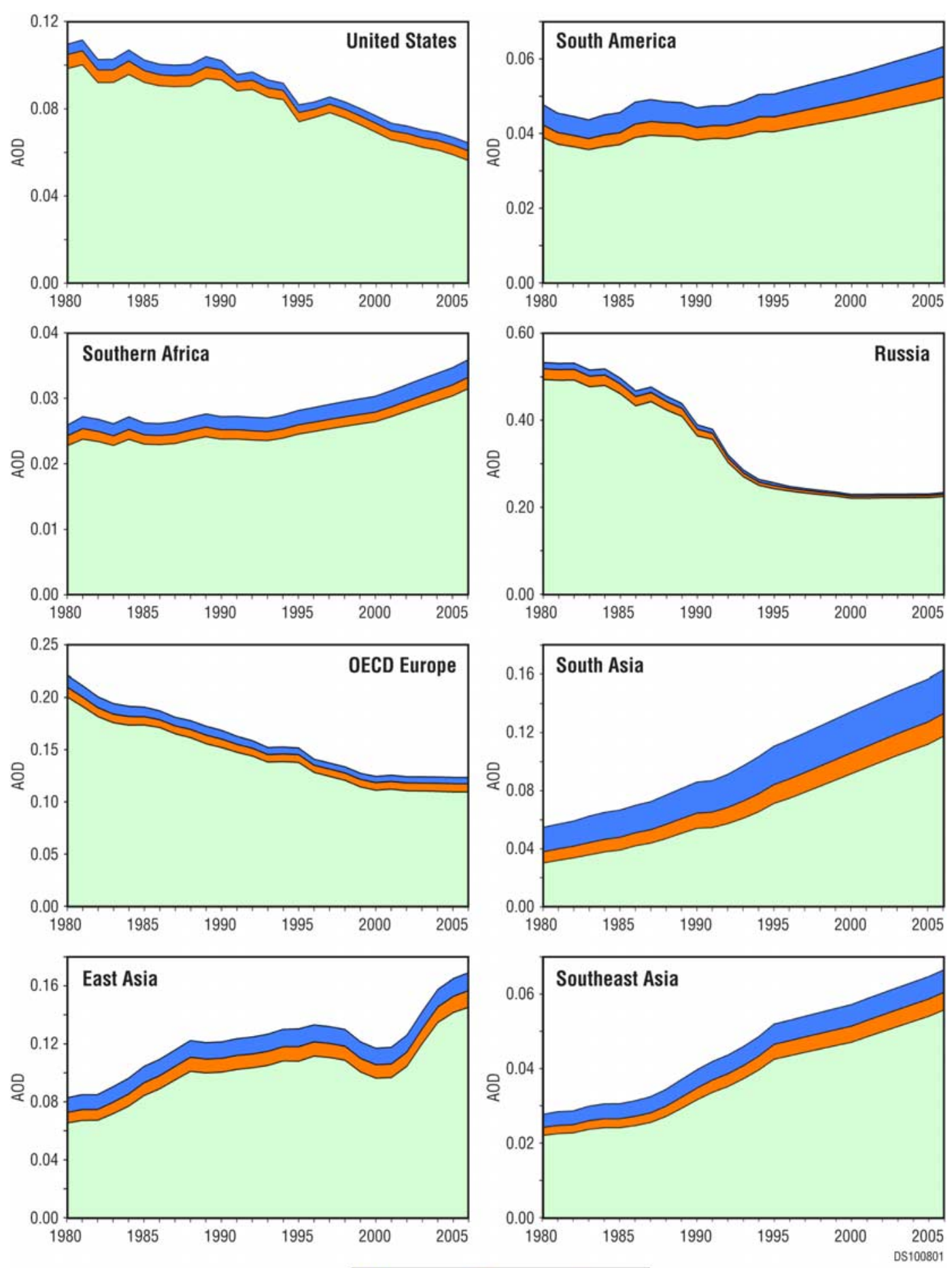

$\square$ OC $\square$ BC $\square$ Sulfur

Figure 5. Estimated AOD trends for anthropogenic aerosols in each region, 1980-2006.

\subsection{Comparisons of AOD and Surface Solar Radiation Observations}

[40] Figure 6 shows comparisons of 5-year central moving averages of the normalized $\exp [-\mathrm{AOD}]$ values and the normalized surface solar radiation observations for each region. Moving averages diminish the interannual fluctuations and make the long-term trends clearer and easier to analyze. We make the following general observations about the trends in each region. For the United States, there appears to have been a period of fairly constant AOD until the early 1990s. After about 1992 there is a period of continuous reduction in AOD (increasing solar radiation), supported by the limited observations beginning in 2000 . We attribute this to sulfate reduction through implementation of $\mathrm{SO}_{2}$ emission reduction measures under the Clean Air Act Amendments of 1990. South America shows an increase in AOD from about 1980 to 1990, followed by a 
Table 4. Average Contributions of Aerosol Types to Estimated AOD From 1980 to $2006^{\mathrm{a}}$

\begin{tabular}{|c|c|c|c|c|c|c|c|c|c|c|}
\hline \multirow[b]{2}{*}{ Region } & \multicolumn{2}{|l|}{$\mathrm{BC}$} & \multicolumn{2}{|l|}{$\mathrm{OC}$} & \multicolumn{2}{|c|}{ Sulfur } & \multirow[b]{2}{*}{ Sea Salt } & \multirow[b]{2}{*}{ Dust } & \multirow[b]{2}{*}{ Anthropogenic } & \multirow[b]{2}{*}{ Natural } \\
\hline & Anthropogenic & Natural & Anthropogenic & Natural & Anthropogenic & Natural & & & & \\
\hline United States & 3.9 & 0.4 & 3.3 & 8.7 & 66.5 & 3.1 & 3.3 & 10.8 & 73.7 & 26.3 \\
\hline South America & 2.2 & 6.2 & 3.4 & 38.5 & 22.9 & 13.3 & 4.2 & 9.3 & 28.6 & 71.4 \\
\hline Southern Africa & 1.6 & 6.8 & 2.3 & 35.5 & 26.5 & 4.6 & 4.3 & 18.5 & 30.4 & 69.6 \\
\hline OECD Europe & 2.8 & 0.7 & 2.7 & 10.5 & 50.9 & 5.9 & 7.0 & 19.5 & 56.4 & 43.6 \\
\hline Russia & 2.7 & 0.2 & 1.8 & 2.3 & 74.1 & 2.1 & 2.0 & 14.9 & 78.5 & 21.5 \\
\hline South Asia & 6.4 & 0.5 & 13.1 & 5.4 & 35.6 & 0.3 & 4.2 & 34.5 & 55.2 & 44.9 \\
\hline East Asia & 4.3 & 0.1 & 5.3 & 2.7 & 45.8 & 0.1 & 5.2 & 36.5 & 55.4 & 44.6 \\
\hline Southeast Asia & 2.6 & 3.7 & 3.9 & 34.3 & 27.8 & 14.0 & 6.3 & 7.5 & 34.3 & 65.7 \\
\hline
\end{tabular}

${ }^{\mathrm{a}}$ Average contribution of aerosol types given in percent.

decrease from 1990 until 2000; after 2001 AOD values return to about the level of the 1980s. We await observational data for South America to compare against. For southern Africa, AOD increases continuously after about 1985. AOD in OECD Europe is stable until about 1993 in the estimates and 2000 in the observations. After 2000 in both records, AOD seems to improve, likely due to environmental control measures that reduced anthropogenic emissions. The statistics, however, are rather poor, because of significant interannual variability, most of which seems to be caused by fluctuating OC contributions from biomass burning. Russia shows a flat trend until 1991 when the Soviet Union broke up [Abakumova et al., 1996]; after that there is a general decrease in AOD, which can be attributed to the phasing out of high-polluting, state-owned, heavy industries under economic pressures. This effect finally seems to have tapered off after about 2000, which may be due to renewed industrial growth.

[41] South Asia shows a steady increase in AOD across the entire study period due to economic and industrial expansion without controls on atmospheric emissions. East Asia has the following three clearly demarcated periods: (1) 1980-1992, corresponding to economic growth and industrial development under the "opening up" policy initiated by Deng Xiaoping in the late 1970s (increasing AOD); (2) 1993-2000, a period of slowed economic growth, coupled with $\mathrm{SO}_{2}$ control policies and other reforms that improved industrial performance and reduced emissions (decreasing AOD); and (3) 2000-2006, a period of unprecedented economic growth (increasing AOD). Southeast Asia is dominated by natural emissions, relative to anthropogenic emissions, particular in 1992 and 1997 when large-scale volcanic eruptions and forest fires occurred. For southeast Asia, no clear long-term trend is apparent in either the estimated AOD or the observed surface solar radiation. For all regions except southeast Asia, we conclude that the directions of the estimated and observed trends are the same, and the same major features are observed.

[42] Figure 7 presents correlation coefficients between the two data series, compared year against year (not moving averages). The correlation coefficient $R$ reflects the closeness of the relationship between the trends of estimated $\exp [-\mathrm{AOD}]$ and observed surface solar radiation. The $R$ values vary between -0.23 and 0.77 . We can say that for four regions, Russia $(R=0.77)$, the United States $(R=$ $0.76)$, south Asia $(R=0.71)$, and southern Africa $(R=0.54)$, agreement is good $(R>0.5)$, indicating that the estimated and observed trends move in the same direction and have a strong linear relationship. It is also good for East Asia up to $1992(R=0.67)$. For OECD Europe $R=0.37$, meaning that the two trends move in the same direction, but the linear dependence is not that strong. Though the two OECD Europe curves have similar features, the observed peak at about 2000 is much stronger in the estimates than in the observations. The unusually hot summer of 2003 in Europe influenced the observed radiation trend noticeably [Wild et $a l ., 2009]$, though it cannot be reflected in our approach. For East Asia as a whole $(R=-0.25)$ and southeast Asia $(R=$ $-0.23), R$ values are negative, suggesting that the estimated and observed trends move in the opposite direction. Interestingly, for East Asia the curves have similar shapes but the observational curve lags the estimated curve by about 4 years, leading to an apparent anticorrelation. It is not easy to explain this time lag, but it may be due to the large number of Japanese monitoring sites in the observational data set. Possibly the observations are weighted to reflect an improvement in Japan that occurred in $\sim 1991$, while the estimates preferentially weigh emissions in China, which did not begin to decline until $\sim 1995$. Detailed modeling studies would be needed to investigate this further. It is particularly hard to explain the apparent increase in solar radiation in East Asia in the latter part of the period (20002005), when we know for certain that $\mathrm{SO}_{2}$ emissions in China increased dramatically during this time period. These inconsistencies with the chosen observational data set for East Asia are puzzling in light of our previous success in estimating AOD trends for China [Streets et al., 2008] before 2000 (which used a different set of observational data from Chinese weather stations). A more detailed analysis of this region by Wild et al. [2009] suggests that surface solar radiation at Chinese sites does indeed tend to decrease after 2000, in agreement with the increase in emissions, whereas the Korean sites show a continuation of the increase, which may dominate the radiation increase shown in East Asia after 2000 in Figure 6.

[43] One reason why the comparison between estimates and observations might be imperfect is possible changes in cloud cover during the 26-year period. Both estimates and observations are all-sky, and therefore the influences of clouds are present in both records. For example, Norris and Wild [2007] showed that over Europe cloud cover slightly decreased during 1971-1986 and slightly increased during 1987-2002, thereby altering the aerosol-induced changes in solar radiation over Europe in the all-sky fluxes. 

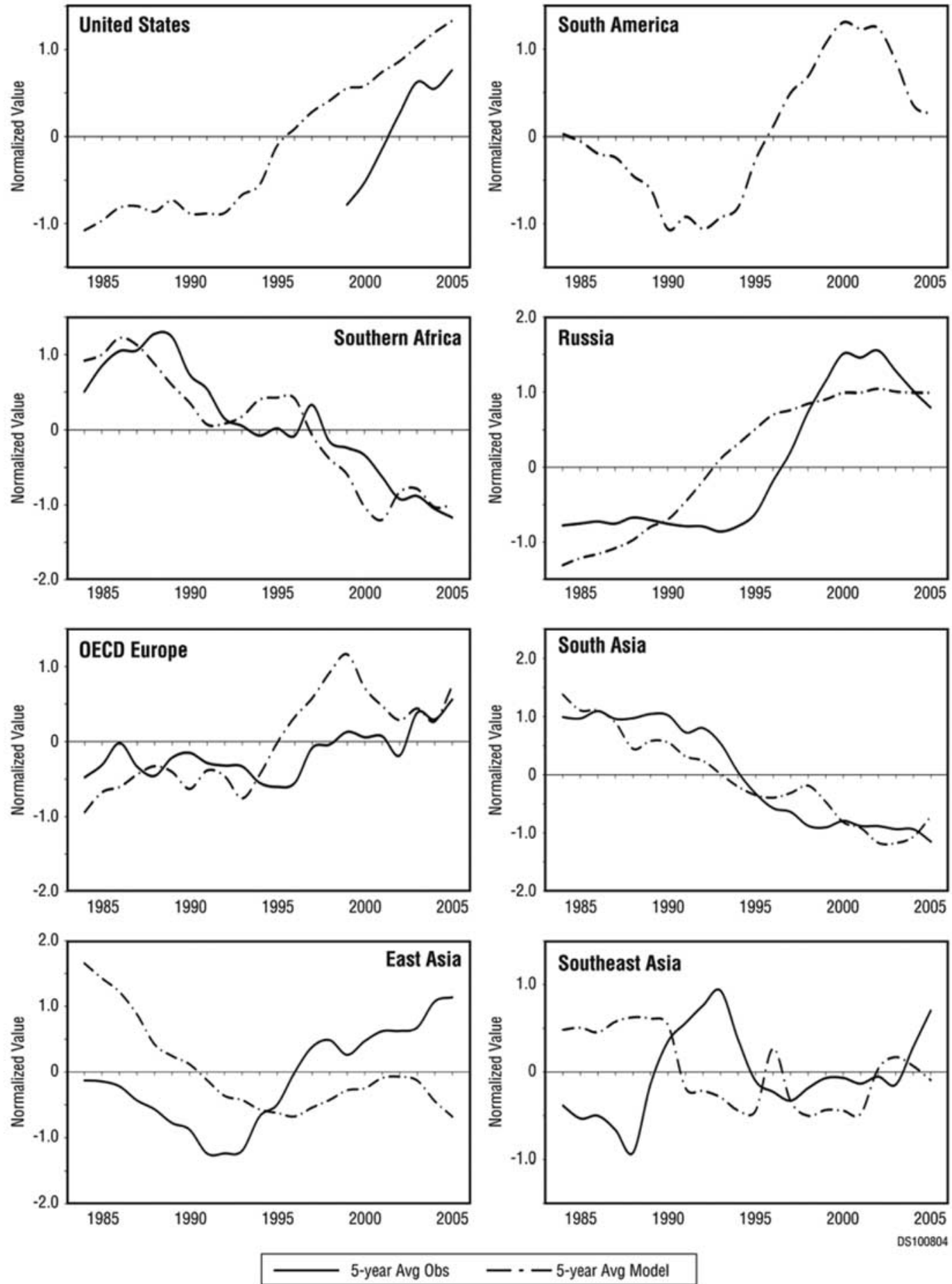

Figure 6. Five-year central moving averages of normalized annual means of observed surface solar radiation and normalized estimated values of $\exp [-\mathrm{AOD}], 1980-2005$.

[44] We conclude that we have been reasonably successful in developing and understanding aerosol trends in different regions of the world. For regions that are dominated by anthropogenic emissions (see Table 4) and for which emissions are generally better known, our predictive capability is the best. For regions with fluctuating emissions due to sporadic volcanic and biomass burning activity, our approach is less successful and for southeast Asia the agreement is poor. One clear reason for this is that emissions such as these occur on time scales much less than 1 year (days to weeks) and only in specific locations. Thus the concepts of annual average emissions and observations are not very meaningful. Also, meteorology during the time of the episode plays an important role in determining the relationship between the source strength and the measurements at a given site. We do not have the luxury of averaging over time and space as we do for man-made emissions. Full model runs for each year would be needed 


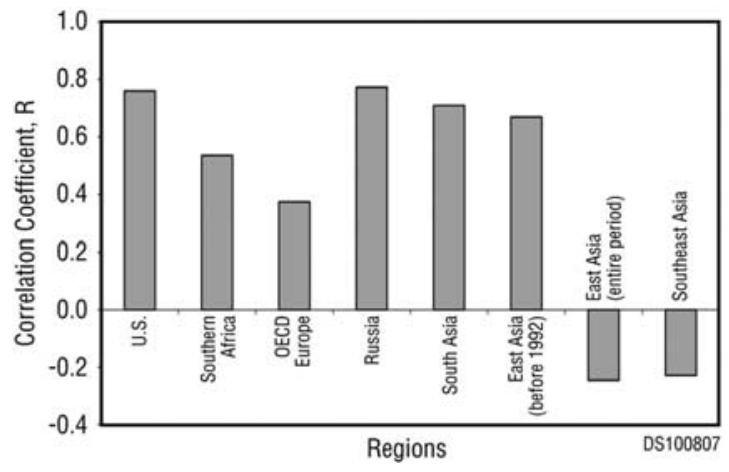

Figure 7. Correlation coefficients $(R)$ between trends of observed surface solar radiation and estimated values of $\exp [-\mathrm{AOD}]$.

to improve the results in such instances. Nevertheless, we believe that studies such as these provide valuable insight into the contributors to aerosol concentrations around the world and the trends that are governing them.

[45] With respect to the topic of the dimming-brightening transition, we certainly see the basis of such a transition in five of the eight world regions studied. According to our estimates, though the graphs are not always unambiguous, the transitions took place in 1991 in the United States, in $\sim 1992$ in South America, in 1990 in Russia, in 1993 in OECD Europe, and 1995 in East Asia. In south Asia and southern Africa the transitions have not yet occurred. However, we also see signs of recent reversals back to dimming in South America and Russia (and possibly China [see Wild et al., 2009]) that may be associated with renewed industrial and economic expansion since 2000.

[46] Results such as those contained in Table 4 provide a foundation for identifying places and source types to focus on to reduce aerosol concentrations and the roles they play in issues such as local and regional air quality degradation and climate change. In future work we will try to narrow our focus even more down to the sectoral contributions to AOD (industry, power, transportation, etc.) in particular countries. We also look forward to comparing our results with full year-by-year GOCART model runs for this time period, presently under way at NASA Goddard Space Flight Center, which will include interannual variations in meteorology, aerosol chemistry, and aerosol transport.

[47] Acknowledgments. The work performed at Argonne National Laboratory was funded by the U.S. Department of Energy, Office of Science, Office of Biological and Environmental Research. The authors gratefully acknowledge the support of Ashley Williamson and Bob Vallario in that office. Argonne National Laboratory is operated by the University of Chicago Argonne, LLC, under contract DE-AC02-06CH11357 with the U.S. Department of Energy. The radiation data archives at ETH Zurich are supported by funding from the Swiss National Centre for Competence in Climate Research (NCCR Climate).

\section{References}

Abakumova, G. M., E. M. Feigelson, V. Russak, and V. V. Stadnik (1996), Evaluation of long-term changes in radiation, cloudiness and surface temperature on the territory of the former Soviet Union, J. Clim., 9, 1319-1327, doi:10.1175/1520-0442(1996)009<1319:EOLTCI >2.0.CO;2. Ackerman, T. P., and G. M. Stokes (2003), The Atmospheric Radiation Measurement Program, Phys. Today, 56, 38-44, doi:10.1063/1.1554135.

Alpert, P., P. Kishcha, Y. J. Kaufman, and R. Schwarzbard (2005), Global dimming or local dimming?: Effect of urbanization on sunlight availability, Geophys. Res. Lett., 32, L17802, doi:10.1029/2005GL023320.
Andres, R. J., and A. D. Kasgnoc (1998), A time-averaged inventory of subaerial volcanic sulfur emissions, J. Geophys. Res., 103, 25,25125,261, doi:10.1029/98JD02091.

Augustine, J. A., J. J. DeLuisi, and C. N. Long (2000), SURFRAD-A national surface radiation budget network for atmospheric research, Bull. Am. Meteorol. Soc., 81, 2341-2357, doi:10.1175/1520-0477(2000)081< 2341:SANSRB $>2.3 . \mathrm{CO} ; 2$.

Bond, T. C., D. G. Streets, K. F. Yarber, S. M. Nelson, J.-H. Woo, and Z. Klimont (2004), A technology-based global inventory of black and organic carbon emissions from combustion, J. Geophys. Res., 109, D14203, doi:10.1029/2003JD003697.

Carn, S. A., A. J. Krueger, G. J. S. Bluth, S. J. Schaefer, N. A. Krotkov, I. M. Watson, and S. Datta (2003), Volcanic eruption detection by the Total Ozone Mapping Spectrometer (TOMS) instruments: A 22-year record of sulphur dioxide and ash emissions, in Volcanic Degassing, Spec. Publ. Geol. Soc. London, vol. 213, edited by C. Oppenheimer, D. M. Pyle, and J. Barclay, pp. 177-202, Geol. Soc. of London, London, U. K.

Carn, S. A., A. J. Krueger, S. Arellano, N. A. Krotkov, and K. Yang (2008), Daily monitoring of Ecuadorian volcanic degassing from space, J. Volcanol. Geotherm. Res., 176, 141 -150, doi:10.1016/j.volgeores.2008.01.029.

Chin, M., R. B. Rood, S.-J. Lin, J.-F. Müller, and A. M. Thompson (2000), Atmospheric sulfur cycle simulated in the global model GOCART: Model description and global properties, J. Geophys. Res., 105, 24,671-24,687, doi:10.1029/2000JD900384.

Chin, M., et al. (2002), Tropospheric aerosol optical thickness from the GOCART model and comparisons with satellite and Sun photometer measurements, J. Atmos. Sci., 59, 461-483, doi:10.1175/15200469(2002)059<0461:TAOTFT >2.0.CO;2.

Chin, M., P. Ginoux, R. Lucchesi, B. Huebert, R. Weber, T. Anderson, S. Masonis, B. Blomquist, A. Bandy, and D. Thornton (2003), A global aerosol model forecast for the ACE-Asia field experiment, J. Geophys. Res., 108(D23), 8654, doi:10.1029/2003JD003642.

Chin, M., et al. (2004), Aerosol distribution in the Northern Hemisphere during ACE-Asia: Results from global model, satellite observations, and Sun photometer measurements, J. Geophys. Res., 109, D23S90, doi:10.1029/2004JD004829.

Chylek, P., U. Lohmann, M. Dubey, M. Mishchenko, R. Kahn, and A. Ohmura (2007), Limits on climate sensitivity derived from recent satellite and surface observations, J. Geophys. Res., 112, D24S04, doi:10.1029/2007JD008740.

Dutton, E. G., D. W. Nelson, R. S. Stone, D. Longenecker, G. Carbaugh, J. M. Harris, and J. Wendell (2006), Decadal variations in surface solar irradiance as observed in a globally remote network, J. Geophys. Res., 111, D19101, doi:10.1029/2005JD006901.

Gerber, H. E. (1985), Relative-humidity parameterization of the Navy Aerosol Model (NAM), Nav. Res. Lab. Rep. 8956, Nav. Res. Lab., Washington, D. C.

Gilgen, H., M. Wild, and A. Ohmura (1998), Means and trends of shortwave irradiance at the surface estimated from Global Energy Balance Archive data, J. Clim., 11, 2042-2061.

Ginoux, P., M. Chin, I. Tegen, J. M. Prospero, B. Holben, O. Dubovik, and S.-J. Lin (2001), Sources and distributions of dust aerosols simulated with the GOCART model, J. Geophys. Res., 106, 20,255-20,273, doi:10.1029/2000JD000053.

Gong, S. L. (2003), A parameterization of sea-salt aerosol source function for sub- and super-micron particles, Global Biogeochem. Cycles, 17(4), 1097, doi:10.1029/2003GB002079.

Guenther, A., T. Karl, P. Harley, C. Wiedinmyer, P. I. Palmer, and C. Geron (2006), Estimates of global terrestrial isoprene emissions using MEGAN (Model of Emissions of Gases and Aerosols from Nature), Atmos. Chem. Phys., 6, 3181-3210.

Hand, J. L., N. M. Mahowald, Y. Chen, R. L. Siefert, C. Luo, A. Subramaniam, and I. Fung (2004), Estimates of atmospheric-processed soluble iron from observations and a global mineral aerosol model: Biogeochemical implications, J. Geophys. Res., 109, D17205, doi:10.1029/ 2004JD004574

Kazahaya, K., H. Shinohara, K. Uto, M. Odai, Y. Nakahori, H. Mori, H. Iino, M. Miyashita, and J. Hirabayashi (2004), Gigantic $\mathrm{SO}_{2}$ emission from Miyakejima volcano, Japan, caused by caldera collapse, Geology, 32, 425-428, doi:10.1130/G20399.1.

Kettle, A. J., et al. (1999), A global database of sea surface dimethylsulfide (DMS) measurements and a procedure to predict sea surface DMS as a function of latitude, longitude, and month, Global Biogeochem. Cycles, 13, 399-444, doi:10.1029/1999GB900004.

Kistler, R., et al. (2001), The NCEP-NCAR 50-year reanalysis: Monthly means CD-ROM and documentation, Bull. Am. Meteorol. Soc., 82, 247267, doi:10.1175/1520-0477(2001)082<0247:TNNYRM $>2.3$.CO 2 .

Klimont, Z., D. G. Streets, S. Gupta, J. Cofala, L. Fu, and Y. Ichikawa (2002), Anthropogenic emissions of non-methane volatile organic compounds in 
China, Atmos. Environ., 36, 1309-1322, doi:10.1016/S13522310(01)00529-5.

Krotkov, N. A., S. A. Carn, A. J. Krueger, P. K. Bhartia, and K. Yang (2006), Band residual difference algorithm for retrieval of $\mathrm{SO}_{2}$ from the AURA Ozone Monitoring Instrument (OMI), IEEE Trans. Geosci. Remote Sens., 44, 1259-1266, doi:10.1109/TGRS.2005.861932.

Kvalevåg, M. M., and G. Myhre (2007), Human impact on direct and diffuse solar radiation during the industrial era, J. Clim., 20, 48744883, doi:10.1175/JCLI4277.1.

Liepert, B. G. (2002), Observed reductions of surface solar radiation at sites in the United States and worldwide from 1961 to 1990, Geophys. Res. Lett., 29(10), 1421, doi:10.1029/2002GL014910.

Liss, P. S., and L. Merlivat (1986), Air-sea gas exchange rates: Introduction and synthesis, in The Role of Air-Sea Exchange in Geochemical Cycling, edited by P. Buat-Ménard, pp. 113-127, D. Reidel, Dordrecht, Netherlands.

Long, C. N., E. G. Dutton, J. A. Augustine, W. Wiscombe, M. Wild, S. A. McFarlane, and C. J. Flynn (2009), Significant decadal brightening of downwelling shortwave in the continental United States, J. Geophys. Res., 114, D00D06, doi:10.1029/2008JD011263.

Luo, C., N. M. Mahowald, and J. del Corral (2003), Sensitivity study of meteorological parameters on mineral aerosol mobilization, transport and distribution, J. Geophys. Res., 108(D15), 4447, doi:10.1029/2003JD003483.

Mahowald, N., C. Luo, J. del Corral, and C. S. Zender (2003), Interannual variability in atmospheric mineral aerosols from a 22-year model simulation and observational data, J. Geophys. Res., 108(D12), 4352, doi:10.1029/2002JD002821.

Mahowald, N. M., J. A. Ballantine, J. Feddema, and N. Ramankutty (2007), Global trends in visibility: Implications for dust sources, Atmos. Chem. Phys., 7, 3309-3339.

Mahowald, N. M., et al. (2009), Atmospheric iron deposition: Global distribution, variability and human perturbations, Annu. Rev. Mar. Sci., 1 , 245-278, doi:10.1146/annurev.marine.010908.163727.

Manktelow, P. T., G. W. Mann, K. S. Carslaw, D. V. Spracklen, and M. P. Chipperfield (2007), Regional and global trends in sulfate aerosol since the 1980s, Geophys. Res. Lett., 34, L14803, doi:10.1029/2006GL028668.

McCormick, M. P., L. W. Thomason, and C. R. Trepte (1995), Atmospheric effects of the Mt Pinatubo eruption, Nature, 373, 399-404, doi:10.1038/ 373399a0

Mishchenko, M. I., and I. V. Geogdzhayev (2007), Satellite remote sensing reveals regional tropospheric aerosol trends, Opt. Express, 15, 74237438, doi:10.1364/OE.15.007423.

Mishchenko, M. I., I. V. Geogdzhayev, W. B. Rossow, B. Cairns, B. E. Carlson, A. A. Lacis, L. Liu, and L. D. Travis (2007), Long-term satellite record reveals likely recent aerosol trend, Science, 315, 1543, doi:10.1126/science. 1136709

Monahan, E. C., D. E. Spiel, and K. L. Davidson (1986), A model of marine aerosol generation via whitecaps and wave disruption, in Oceanic Whitecaps, edited by E. C. Monahan and G. Mac Niocaill, pp. 167-174, D. Reidel, Dordrecht, Netherlands.

Nakicenovic, N., et al. (2000), Emissions Scenarios: A Special Report of Working Group III of the Intergovernmental Panel on Climate Change, Cambridge Univ. Press, New York.

National Institute for Public Health and the Environment (2001), The IMAGE 2.2 implementation of the SRES scenarios [CD-ROM], Natl. Inst. Public Health Environ. Publ. 481508018, Bilthoven, Netherlands.

Newhall, C. G., and S. Self (1982), The Volcanic Explosivity Index (VEI): An estimate of explosive magnitude for historical volcanism, J. Geophys. Res., 87, 1231-1238, doi:10.1029/JC087iC02p01231.

Norris, J. R., and M. Wild (2007), Trends in aerosol radiative effects over Europe inferred from observed cloud cover, solar "dimming," and solar "brightening" (2007), J. Geophys. Res., 112, D08214, doi:10.1029/ 2006JD007794.

Ohmura, A., et al. (1998), Baseline Surface Radiation Network (BSRN/ WCRP): New precision radiometry for climate research, Bull. Am. Meteorol. Soc., 79, 2115-2136, doi:10.1175/1520-0477(1998)079<2115:BSRNBW> 2.0.CO;2.

Pinker, R. T., B. Zhang, and E. G. Dutton (2005), Do satellites detect trends in surface solar radiation?, Science, 308, 850-854, doi:10.1126/ science. 1103159.

Ramanathan, V., P. J. Crutzen, J. T. Kiehl, and D. Rosenfeld (2001), Aerosols, climate and the hydrological cycle, Science, 294, 2119-2124, doi:10.1126/science.1064034.

Ramanathan, V., C. Chung, D. Kim, T. Bettge, L. Buja, J. T. Kiehl, W. M. Washington, Q. Fu, D. R. Sikka, and M. Wild (2005), Atmospheric brown clouds: Impacts on south Asian climate and hydrological cycle, Proc. Natl. Acad. Sci. U. S. A., 102, 5326-5333, doi:10.1073/pnas.0500656102.

Remer, L. A., et al. (2008), Global aerosol climatology from the MODIS satellite sensors, J. Geophys. Res., 113, D14S07, doi:10.1029/ 2007JD009661.
Romanou, A., B. Liepert, G. A. Schmidt, W. B. Rossow, R. A. Ruedy, and Y. Zhang (2007), 20th century changes in surface solar irradiance in simulations and observations, Geophys. Res. Lett., 34, L05713, doi:10.1029/2006GL028356.

Ruckstuhl, C., et al. (2008), Aerosol and cloud effects on solar brightening and the recent rapid warming, Geophys. Res. Lett., 35, L12708, doi:10.1029/2008GL034228.

Saltzman, E. S., D. B. King, K. Holmen, and C. Leck (1993), Experimental determination of the diffusion coefficient of dimethylsulfide in water, J. Geophys. Res., 98, 16,481-16,486, doi:10.1029/93JC01858.

Schnell, R. C. (Ed.) (2004), Climate Monitoring and Diagnostics Laboratory summary report, 2002-2003, Rep. 27, 174 pp., Natl. Oceanic Atmos Admin., Boulder, Colo.

Schnetzler, C. C., G. J. S. Bluth, A. J. Krueger, and L. S. Walter (1997), A proposed volcanic sulfur dioxide index (VSI), J. Geophys. Res., 102, 20,087-20,091, doi:10.1029/97JB01142.

Schubert, S. R., R. B. Rood, and J. Pfaendtner (1993), An assimilated dataset for Earth science applications, Bull. Am. Meteorol. Soc., 74 2331 -2342, doi:10.1175/1520-0477(1993)074<2331:AADFES >2.0. $\mathrm{CO} ; 2$.

Schultz, M. G., et al. (2007), RETRO emission data sets and methodologies for estimating emissions, Reanal. Tropospheric Chem. Compos. Proj. Rep., Max Planck Inst. for Meteorol., Hamburg, Germany.

Schultz, M. G., A. Heil, J. J. Hoelzemann, A. Spessa, K. Thonicke, J. G. Goldammer, A. C. Held, J. M. C. Pereira, and M. van het Bolscher (2008), Global wildland fire emissions from 1960 to 2000, Global Biogeochem. Cycles, 22, GB2002, doi:10.1029/2007GB003031.

Schulz, M., et al. (2006), Radiative forcing by aerosols as derived from the AeroCom present-day and pre-industrial simulations, Atmos. Chem. Phys., 6, 5225-5246.

Schwartz, R. D. (2005), Global dimming: Clear-sky atmospheric transmission from astronomical extinction measurements, J. Geophys. Res., 110, D14210, doi:10.1029/2005JD005882.

Sheridan, P. J., and J. A. Ogren (1999), Observations of the vertical and regional variability of aerosol optical properties over central and eastern North America, J. Geophys. Res., 104, 16,793-16,806, doi:10.1029/ 1999JD900241.

Siebert, L., and T. Simkin (2008), Volcanoes of the World: An Illustrated Catalog of Holocene Volcanoes and Their Eruptions, http://www.volcano. si.edu/world/, Smithson. Inst., Washington, D. C.

Smith, S. J., H. Pitcher, and T. M. L. Wigley (2001), Global and regional anthropogenic sulfur dioxide emissions, Global Planet. Change, 29, 99119, doi:10.1016/S0921-8181(00)00057-6.

Stanhill, G., and S. Cohen (2001), Global dimming: A review of the evidence for a widespread and significant reduction in global radiation with discussion of its probable cause and possible agricultural consequences, Agric. For. Meteorol., 107, 255-278, doi:10.1016/S01681923(00)00241-0.

Streets, D. G., N. Y. Tsai, H. Akimoto, and K. Oka (2000), Sulfur dioxide emissions in Asia in the period 1985-1997, Atmos. Environ., 34, 44134424, doi:10.1016/S1352-2310(00)00187-4.

Streets, D. G., et al. (2003), An inventory of gaseous and primary aerosol emissions in Asia in the year 2000, J. Geophys. Res., 108(D21), 8809, doi:10.1029/2002JD003093.

Streets, D. G., T. C. Bond, T. Lee, and C. Jang (2004), On the future of carbonaceous aerosol emissions, J. Geophys. Res., 109, D24212, doi:10.1029/2004JD004902.

Streets, D. G., Y. Wu, and M. Chin (2006), Two-decadal aerosol trends as a likely explanation of the global dimming/brightening transition, Geophys. Res. Lett., 33, L15806, doi:10.1029/2006GL026471.

Streets, D. G., C. Yu, Y. Wu, M. Chin, Z. Zhao, T. Hayasaka, and G. Shi (2008), Aerosol trends over China, 1980-2000, Atmos. Res., 88, 174182

van der Werf, G., J. T. Randerson, L. Giglio, G. J. Collatz, P. S. Kasibhatla, and A. F. Arellano (2006), Interannual variability in global biomass burning emissions from 1997 to 2004, Atmos. Chem. Phys., 6, 3423 3441 .

Wild, M. (2009), Global dimming and brightening: A review, J. Geophys. Res., 114, D00D16, doi:10.1029/2008JD011470.

Wild, M., A. Ohmura, H. Gilgen, and D. Rosenfeld (2004), On the consistency of trends in radiation and temperature records and implications for the global hydrological cycle, Geophys. Res. Lett., 31, L11201, doi:10.1029/2003GL019188.

Wild, M., et al. (2005), From dimming to brightening: Decadal changes in solar radiation at Earth's surface, Science, 308, 847-850, doi:10.1126/ science. 1103215 .

Wild, M., A. Ohmura, and K. Makowski (2007), Impact of global dimming and brightening on global warming, Geophys. Res. Lett., 34, L04702, doi:10.1029/2006GL028031. 
Wild, M., J. Grieser, and C. Schär (2008), Combined surface solar brightening and increasing greenhouse effect support recent intensification of the global land-based hydrological cycle, Geophys. Res. Lett., 35, L17706, doi:10.1029/2008GL034842.

Wild, M., B. Trüssel, A. Ohmura, C. N. Long, G. König-Langlo, E. G. Dutton, and A. Tsvetkov (2009), Global dimming and brightening An update beyond 2000, J. Geophys. Res., 114, D00D13, doi:10.1029/ 2008JD011382.

World Climate Research Programme (1991), Radiation and climate: Workshop on implementation of the baseline surface radiation network (Washington, DC, U.S.A., 3-5 December 1990), World Clim. Res. Prog. Rep. 54/World Meteorol. Organ. Rep. 406, World Meteorol. Organ., Geneva, Switzerland.

Xia, X., Z. Li, P. Wang, H. Chen, and M. Cribb (2007), Estimation of aerosol effects on surface irradiance based on measurements and radiative transfer model simulations in northern China, J. Geophys. Res., 112, D22S10, doi:10.1029/2006JD008337.

Zender, C. S., H. Bian, and D. Newman (2003), Mineral Dust Entrainment and Deposition (DEAD) model: Description and 1990s dust climatology, J. Geophys. Res., 108(D14), 4416, doi:10.1029/2002JD002775.
Zhao, T. X.-P., I. Laszlo, W. Guo, A. Heidinger, C. Cao, A. Jelenak, D. Tarpley, and J. Sullivan (2008), Study of long-term trend in aerosol optical thickness observed from operational AVHRR satellite instrument, J. Geophys. Res., 113, D07201, doi:10.1029/2007JD009061.

M. Chin and T. Diehl, NASA Goddard Space Flight Center, Mail Code 130, Greenbelt, MD 20771, USA.

N. Mahowald, Department of Earth and Atmospheric Sciences, Cornell University, 2140 Snee Hall, Ithaca, NY 14853, USA.

M. Schultz, Forschungszentrum Juelich, Wilhelm-Johnen-Strasse, D-52425 Juelich, Germany.

D. G. Streets, F. Yan, and C. Yu, Argonne National Laboratory, 9700 South Cass Avenue, Argonne, IL 60439, USA. (dstreets@anl.gov)

M. Wild, Institute for Atmospheric and Climate Science, ETH Zurich, Universitaetstrasse 16, CH-8092 Zurich, Switzerland.

Y. Wu, Department of Environmental Science and Engineering, Tsinghua University, Beijing 100084, China. 